\title{
Efficacy and safety of risperidone long-acting injection in elderly people with schizophrenia
}

This article was published in the following Dove Press journal:

Clinical Interventions in Aging

25 August 2009

Number of times this article has been viewed

\author{
Dhiren Singh ${ }^{1,2}$ \\ Daniel W O'Connor' \\ 'Department of Psychological \\ Medicine, Monash University, \\ Melbourne, Australia; ${ }^{2}$ Peninsula \\ Mental Health Service, Melbourne, \\ Australia
}

Correspondence: Dhiren Singh Aged Persons Mental Health Service, Peninsula Health, Frankston Hospital, Hastings Road, Frankston, Victoria 3199, Australia

Tel +6I 397846999

Fax +6I 397846990

Email dsingh@phcn.vic.gov.au

\begin{abstract}
Antipsychotic medication is the mainstay of treatment in elderly patients with psychosis. In recent years, second generation antipsychotics have come to be preferred. Longacting risperidone is the first such antipsychotic available for use in this vulnerable group of patients and offers an attractive alternative to traditional medications. The available literature revealed that long-acting risperidone is generally well tolerated and is effective in treating both the positive and negative symptoms of schizophrenia. Despite a lack of randomized trials and head-to-head studies, it appears to be a useful addition to the treatment armory for patients with chronic psychosis who require a depot preparation. Further research into its endocrine and metabolic side effects is needed.
\end{abstract}

Keywords: risperidone, long-acting injection, old age, efficacy, safety

\section{Introduction}

The key feature of psychosis is the misinterpretation of reality as shown by altered perceptions, false beliefs, and disorganized patterns of speech and behavior. In the elderly, psychotic symptoms arise in a number of conditions: schizophrenia, schizoaffective disorder, delusional disorder, mood disorder, delirium secondary to medical conditions, and neurodegenerative conditions including Alzheimer's disease, vascular dementia, dementia with Lewy bodies and Parkinson's disease. Social isolation, sensory deficits, and polypharmacy are additional risk factors. ${ }^{1}$

Approximately $15 \%$ of all patients with schizophrenia have an onset of symptoms after the age of 40 years, $7 \%$ after the age of 50 and $3 \%$ thereafter. ${ }^{2}$ Hallucinations and persecutory delusions are common and generally follow a chronic course. ${ }^{3}$ In people with Alzheimer's disease, the prevalence of psychotic symptoms ranges from $30 \%$ to $50 \%{ }^{4}$ In dementia with Lewy bodies, visual hallucinations occur in $80 \%$ of cases while auditory hallucinations and paranoid delusions have a prevalence of $20 \%$ and $65 \%$, respectively. ${ }^{5}$ Between $20 \%$ and $60 \%$ of people with Parkinson's disease develop psychotic symptoms. ${ }^{6}$ Psychotic symptoms can be associated with aggressive or disruptive behavior, are a source of distress to caregivers, and often result in

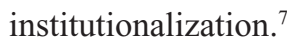

Antipsychotic medications form the mainstay of treatment of psychotic symptoms. In recent years, second generation antipsychotics like risperidone, olanzapine, and clozapine have been preferred over older drugs like haloperidol because of their lower incidence of extrapyramidal, anticholinergic and cardiac side effects and a possible greater efficacy in reducing negative and neurocognitive symptoms. ${ }^{8}$ 
Treatment nonadherence is one of the greatest challenges facing prescribers with $20 \%$ to $50 \%$ of all patients failing to comply fully with medical recommendations. ${ }^{9}$ Rates of nonadherence to antipsychotic prescriptions are even higher. In the large, prospective CATIE Schizophrenia Study on the effectiveness of antipsychotics, for example, $75 \%$ of patients discontinued treatment within 18 months. ${ }^{10}$ Risk factors for nonadherence include ongoing psychosis, limited insight, adverse reactions, stigma, and poor rapport with the treating clinician. ${ }^{11}$ In addition, older people may have difficulty taking medications correctly because of sensory impairment, cognitive deficits, medical co-morbidity, polypharmacy, and heightened sensitivity to adverse effects. ${ }^{12}$

For patients with psychosis who will not or cannot take oral medication on a regular basis a long-acting injectable antipsychotic may offer a solution. Until recently choice was limited to first generation preparations such as haloperidol decanoate and flupenthixol decanoate, all of which can provoke parkinsonism, unsteadiness, and falls to which the elderly are vulnerable. Long-acting risperidone injection is the first "atypical" or second generation antipsychotic freely available for the treatment of psychosis.

This paper focuses on this treatment formulation and its use in the older patients with schizophrenia and related psychoses. Suitable papers were identified by means of an electronic search of MEDLINE, EMBASE, Scopus, PsycINFO and CINAHL databases using combinations of the key terms "risperidone", "antipsychotic agents", "therapeutic use", "adverse effects", and "aged".

\section{Pharmacology of risperidone long-acting injection}

Both risperidone and its active metabolite 9-hydroxy risperidone are thought to have antipsychotic potency. ${ }^{13}$ Long-acting risperidone injection is an extended release microsphere formulation of risperidone encapsulated in polyglactin for intramuscular injection. Traditional antipsychotic depot preparations are esterified and delivered in an oil-based suspension. Because of its lack of a hydroxyl group, risperidone cannot be esterified, but its encapsulation in biodegradable polymer microspheres makes possible its delivery in a water-based vehicle. The polymer dissolves into water and carbon end products, providing a steady release of medication.

After a single intramuscular injection, less than $1 \%$ of the dose is released followed by a lag of three weeks, which makes it necessary to prescribe an oral antipsychotic during this time. From that point on, release occurs steadily between weeks 4 to 6 and subsides by week 7 . Thereafter, twice-weekly injections result in sustained therapeutic plasma concentrations that persist for four to six weeks after the last injection The elimination phase is complete at seven to eight weeks following microsphere breakdown.

The pharmacokinetics of long-acting risperidone is linear in the dose range of 25 to $50 \mathrm{mg}$. Following extensive firstpass metabolism of risperidone by the liver, $90 \%$ is bound in plasma to albumin and alpha-1 acid glycoprotein prior to elimination via the kidneys. Plasma levels are normal in patients with hepatic insufficiency, but may be raised by $60 \%$ in patients with renal impairment. ${ }^{14}$

Since aging is associated with decreased rates of renal blood flow, glomerular filtration and renal clearance as well as reduced levels of synthesis and activity of hepatic microsomal enzymes, caution is required in older patients with renal or hepatic impairment. An age-related fall in total body water results in higher plasma concentrations of this water-based medication, increasing both its activity and the potential for adverse effects. Reduced cerebrovascular perfusion and the increased sensitivity of alpha-1 adrenergic receptors also make the elderly more susceptible to orthostatic hypotension, dizziness and falls. With age, the loss of ascending dopaminergic neurones and postsynaptic dopamine receptors can halve the levels of striatal dopamine by age 65 years, resulting in parkinsonism and tardive dyskinesia given risperidone's high affinity for dopaminergic D2 receptors. ${ }^{12,15}$

Risperidone must be used with caution with other centrally acting medicines. It antagonizes the effects of levodopa and other dopamine agonists and potentiates the orthostatic effects of tricyclic antidepressants and antihypertensives. Caution is advised when combining risperidone with drugs known to prolong the QT interval because of the risk of cardiac arrhythmias. Risperidone levels are increased by cytochrome 450 2D6 inhibitors such as paroxetine and fluoxetine and decreased by cytochrome 450 3A4 inducers like carbamazepine, corticosteroids, and barbiturates.

\section{Efficacy}

Long-acting risperidone proved effective, safe, and tolerable in a large, 12-week randomized, controlled trial in younger adults with schizophrenia. Positive and negative symptoms of schizophrenia improved significantly; adverse reactions were infrequent at low doses, and most patients rated injection pain as low. ${ }^{16}$ There were also improvements in positive and negative symptoms, extrapyramidal side-effects and patient satisfaction in a six-month open label study of patients with 
schizophrenia and other psychoses as they transitioned to long-acting risperidone from other antipsychotics. ${ }^{17}$ In a retrospective case-note audit of patients prescribed long-acting risperidone over a 35-month period, total inpatient days fell from 4,550 to 2,188 following treatment initiation. ${ }^{18}$

In a secondary analysis of findings from an open-label, 50-week trial of long-acting risperidone injection, 57 older patients (mean age 71 years) with clinically stable schizophrenia or schizoaffective disorder received $25 \mathrm{mg}$ to $75 \mathrm{mg}$ every two weeks. ${ }^{19}$ Oral risperidone was prescribed two weeks before and three weeks after the first injection. Dosing was guided by clinical judgment. Thirteen of the 57 patients terminated treatment early, mostly because of withdrawal of consent. Clinical improvement, defined as a fall of $20 \%$ or more in scores on the Positive and Negative Symptom Scale, occurred in $42 \%$ and $62 \%$ of those in the $25 \mathrm{mg}$ and $50 \mathrm{mg}$ groups, respectively. Scores on the Clinical Global Improvement scale fell by at least one point in $37 \%$ and $76 \%$, respectively. Too few patients took $75 \mathrm{mg}$ to provide meaningful results. Improvements were also noted on each of the 10 sub-scales of the 36-item Medical Outcomes Short-Form (SF-36) quality of life scale.

Similar findings emerged from another secondary analysis of data from the six-month, open-label Switch to Risperidone Microspheres (StoRMi) study concerning 52 older patients (mean age 71 years) with clinically stable schizophrenia or schizoaffective disorder. ${ }^{20}$ Doses at study end were $25 \mathrm{mg}$ (60\%), $37.5 \mathrm{mg}$ (26\%), and $50 \mathrm{mg}(14 \%)$ every two weeks. There were 10 discontinuations, mostly due to adverse events. At study end, $47 \%$ of patients had an improvement of $20 \%$ or more in Positive and Negative Symptom Scale scores. There were also statistically significant improvements in scores on the Clinical Global Improvement scale, Extrapyramidal Symptom Rating Scale, SF-36 scale, and patient satisfaction scale.

Case series were typically small. In a review of six patients (mean age 72 years) treated with fortnightly doses of either $25 \mathrm{mg}$ or $37.5 \mathrm{mg}$ long-acting risperidone, two demonstrated long-term clinical improvement. ${ }^{21}$ Of the 18 patients (mean age 71 years) in another series, 12 required $37.5 \mathrm{mg}$ per fortnight, three were given $50 \mathrm{mg}$, and one was given $75 \mathrm{mg}$. All experienced some symptomatic improvement and four became free of all positive and negative symptoms. ${ }^{22}$ Finally, in a retrospective chart review of 48 elderly patients with schizophrenia, $60 \%$ of 25 patients treated with 25 to $50 \mathrm{mg}$ long-acting risperidone achieved strictly defined symptomatic remission after six months. The majority $(72 \%)$ were rated as improved or much improved on the CGI scale, and all but six persisted with treatment over this period. Unspecified side effects were rated as moderate in five cases and severe in two others. ${ }^{23}$

\section{Safety and tolerability}

Risperidone is a selective monoaminergic antagonist with a high affinity with serotonergic 5-HT2 and dopaminergic D2 receptors. It also binds to alpha-1 adrenergic receptors and, to a lesser extent, to $\mathrm{H} 1$ histaminergic and alpha-2 adrenergic receptors. It has no affinity with cholinergic receptors and therefore has no anticholinergic side effects. ${ }^{13}$ Problems with sedation, orthostatic hypotension and rhinitis may be related to its alpha- 1 antagonistic properties. ${ }^{13}$ Risperidone is associated with less weight gain than other second generation antipsychotics, presumably because of its lower affinity with histamine-1 receptors. ${ }^{13,19,22}$ Because of its greater blockade of nigrostriatal dopaminergic D2 receptors than other atypical antipsychotics, it can lead to extrapyramidal side effects, especially at higher doses. ${ }^{12,13}$

In the secondary analysis described above of 57 elderly patients receiving long-acting risperidone, $74 \%$ of all patients reported adverse effects. ${ }^{19}$ Events reported by more than $10 \%$ were insomnia (14\%), constipation (12\%), bronchitis (12\%), psychosis $(11 \%)$, and rhinitis (11\%). A death due to myocardial infarction was judged not to be related to treatment. Scores on the Extrapyramidal Symptom Rating Scale (ESRS) fell by $30 \%$; there were no new cases of tardive dyskinesia, and no significant changes in electrocardiogram parameters. An increase in weight of more than $7 \%$ was seen in none of those taking $25 \mathrm{mg}$ and in $29 \%$ and $89 \%$ of those taking $50 \mathrm{mg}$ and $75 \mathrm{mg}$ doses respectively. After the first injection, five patients reported mild pain and five reported moderate pain. On a visual analogue scale ranging from zero to 100 , pain ratings fell from 8 initially to 2 at study end.

In the other secondary analysis outlined previously concerning 52 elderly patients, the adverse effects of long-acting risperidone were monitored at baseline and then one, three, and six months later. ${ }^{20}$ Adverse events occurring in more than $5 \%$ of cases were as follows: parkinsonism (15\%), other extrapyramidal disorders $(15 \%)$, tremor $(8 \%)$, depression $(6 \%)$, diarrhoea (6\%), dizziness (6\%), and insomnia (6\%). ${ }^{20}$ Events leading to discontinuation included one case each of worsened psychosis, parkinsonism, other extrapyramidal disorder, depression, a suicide attempt and urinary tract infection. Most adverse events were considered mild (53\%) or moderate (34\%). One patient developed tardive dyskinesia and another diabetes but there were no cerebrovascular or prolactin-related events and no significant change in weight. 
Extrapyramidal side effects (tremor, tardive dyskinesia with bradykinesia, and bradykinesia with rigidity) were the reasons given for discontinuation in three patients in a case series of six treated with long-acting risperidone injection. ${ }^{21}$ In another case series of 18 patients, adverse effects were uncommon with only two patients stopping treatment because of extrapyramidal symptoms. ${ }^{22}$ Treatment was continued despite one report each of sedation, modest weight gain, and a transient ischemic attack. ${ }^{22}$

\section{Specific concerns}

No evidence has emerged from the studies cited above of increased cerebrovascular events though the number of patients was relatively small and few were very old. This is an important matter given the concerns that second generation antipsychotics might be responsible for increased cerebrovascular events and mortality in patients with dementia. The Committee on Safety of Medications in the United Kingdom, having reviewed the literature on the use of risperidone and olanzapine for the treatment of behavioral and psychological symptoms of dementia, concluded that each was associated with at least a two-fold increase in the risk of stroke and therefore should not be prescribed in dementia. ${ }^{24}$ Subsequently, a meta-analysis of mortality in 17 placebo-controlled trials of four atypical antipsychotics (aripiprazole, olanzapine, quetiapine, and risperidone) found a pooled incidence of mortality of $3.5 \%$ versus $2.3 \%$ for placebo, a small but statistically significant difference. ${ }^{25}$ These findings were not replicated, however, in a population linkage study of stroke in older people prescribed risperidone or olanzapine. ${ }^{26}$

None of the studies considered here addressed concerns regarding prolactin. Risperidone and conventional antipsychotics raise prolactin levels by blocking dopamine in the tuberoinfundibular pathway. ${ }^{27}$ The short-term effects of raised prolactin include sexual dysfunction and loss of libido while longer-term problems include decreased bone density and osteoporosis to which patients with schizophrenia may be predisposed by risk factors such as sedentary lifestyle, smoking and poor nutrition. ${ }^{27,28}$ Further research of this matter in vulnerable aged patients is clearly necessary.

\section{Conclusions}

On balance, long-acting risperidone injection is effective, generally well tolerated and safe in late-life psychosis and is a useful treatment modality for patients who find it difficult to take tablets. Based on published case series, the manufacturers' recommended dose of $25 \mathrm{mg}$ fortnightly can be safely doubled in some cases. The commonest dose in two series was $37.5 \mathrm{mg} .{ }^{21,22}$
It seems reasonable to start depot treatment at a dose of $25 \mathrm{mg}$ fortnightly after a period of treatment with oral risperidone ( 0.5 to $3 \mathrm{mg}$ daily) to confirm tolerability. Oral supplementation is required for three weeks after the first injection. ${ }^{14}$ Extrapyramidal side effects do occur and should be monitored regularly. There is no evidence to date of an increase in cerebrovascular events but raised prolactin levels with consequent osteoporosis warrant further study as do glucose control and lipid function in genuinely old people. ${ }^{19}$ Further controlled trials and case series are required to fill these gaps in knowledge.

\section{Disclosures}

The authors have no conflicts of interest to declare.

\section{References}

1. Targum SD, Abbott JL. Psychosis in the elderly: a spectrum of disorders. J Clin Psychiatry. 1999;60(Suppl 8):4-10.

2. Harris MJ, Jeste DV. Late-onset schizophrenia: an overview. Schizophr Bull. 1988;14(1):39-55.

3. Trans-Johnson TK, Krull AJ, Jeste DV. Late-life schizophrenia and its treatment: pharmacologic issues in older schizophrenia patients. Clin Geriatr Med. 1992;8:401-410.

4. Jeste DV, Finkel SI. Psychosis of Alzheimer's disease and related dementias. Diagnostic criteria for a distinct syndrome. Am J Geriatr Psychiatry. 2000;8:29-34.

5. McKeith IG, Fairburn A, Bothwell RA, et al. An evaluation of the predictive validity and inter-rater reliability of clinical diagnostic criteria for senile dementia of Lewy body type. Neurology. 1994;44:872-877.

6. Kuzuhara S. Drug-induced psychotic symptoms in Parkinson's disease. Problems, management and dilemma. J Neurol. 2001;248(Suppl 3): III28-III31.

7. Karim S, Byrne EJ. Treatment of psychosis in elderly people. Adv Psychiatr Treat. 2005;11:286-296.

8. Ritchie CW, Chiu E, Halliday S, et al. A comparison of the efficacy and safety of olanzapine and risperidone in the treatment of elderly patients with schizophrenia: an open study of six months duration. Int J Geriatr Psychiatry. 2006;21:171-179.

9. Malhotra S, Karan RS, Pandhi P, et al. Drug related medical emergencies in the elderly: role of adverse drug reactions and non-compliance. Postgrad Med J. 2001;77:703-707.

10. Leiberman JA, Stroup TS, McEvoy JP, et al. Effectiveness of antipsychotic drugs in patients with chronic schizophrenia. $N$ Engl J Med. 2005;353:1209-1223.

11. Perkins DO. Predictors of non-compliance in patients with schizophrenia. J Clin Psychiatry. 2002;63:1121-1128.

12. Masand PS, Gupta S. Long-acting injectable antipsychotics in the elderly. Drugs Aging. 2003;20:1099-1110.

13. Stahl SM. Antipsychotic agents. In: Stahl's Essential Psychopharmacology. Neuroscientific Basis and Practical Applications. 3rd ed. New York, NY: Cambridge University Press; 2008. pp. 327-453.

14. MIMS Australia. Risperdal Consta. MIMS online. 2009. Accessed May 21, 2009. Available from: http://www.mims.com.au/.

15. Volkow ND, Wang GJ, Fowler JS, et al. Parallel loss of presynaptic and post synaptic dopamine markers in normal ageing. Ann Neurol. 1998;44:143-147.

16. Kane JM, Eerdekens M, Lindenmayer JP, et al. Long-acting injectable risperidone: efficacy and safety of the first long-acting atypical antipsychotic. Am J Psychiatry. 2003;160:1125-1132.

17. Möller HJ, Liorca PM, Sacchetti E, et al. Efficacy and safety of direct transition to risperidone long-acting injectable in patients treated with various antipsychotic therapies. Int Clin Psychopharmacol. 2005;20:121-130. 
18. Niaz OS, Haddard PM. Thirty five months experience of risperidone long-acting injection in a UK psychiatric service including mirror image analysis of in-patient care. Acta Psychiatr Scand. 2007;116:36-46.

19. Lasser RA, Bossie CA, Zhu Y, et al. Efficacy and safety of long-acting risperidone in elderly patients with schizophrenia and schizoaffective disorder. Int J Geriatr Psychiatry. 2004;19:898-905.

20. Kissling W, Glue P, Medori R, Simpson S. Long term safety and efficacy of long-acting risperidone in elderly psychotic patients. Hum Psychopharmacol Clin Exp. 2007;22:505-513.

21. Hudson-Jessop P, Hughes B, Brinkley N. New for old? Risperidone long-acting injection in older patients. Australas Psychiatry. 2007; 15:461-464.

22. Singh D, O' Connor DW. Depot risperidone: the experience of an Australian aged psychiatry service. Int Psychogeriatr. 2007;19:789-792.

23. Tadger S, Baruch Y, Barak Y. Symptomatic remission in elderly schizophrenia patients treated with long-acting risperidone. Int Psychogeriatr. 2008;20:1245-1250.
24. Committee on Safety of Medicines. Atypical anti-psychotic drugs and stroke. 2004. Accessed May 21, 2009. Available from: http://www.mca.gov.uk/auwork/monitorsafequalmed/safetymessages/ antipsychotic_qa.htm.

25. Schneider LS, Dagerman KS, Insel P. Risk of death with atypical antipsychotic drug treatment for dementia. Meta-analysis of randomized placebo- controlled trials. JAMA. 2005;294:1934-1943.

26. Herrmann N, Mamdani M, Lanctot KL. Atypical antipsychotics and the risk of cerebrovascular accidents. Am J Psychiatry. 2004;161: 1113-1115.

27. Petty RG. Prolactin and antipsychotic medication: mechanism of action. Schizophr Res. 1999;35(Suppl):S67-S73.

28. Maguire GA. Prolactin elevation with antipsychotic medication: mechanism of action and clinical consequences. J Clin Psychiatry. 2002;63(Suppl 4):S56-S62.
Clinical Interventions in Aging

\section{Publish your work in this journal}

Clinical Interventions in Aging is an international, peer-reviewed journal focusing on evidence-based reports on the value or lack thereof of treatments intended to prevent or delay the onset of maladaptive correlates of aging in human beings. This journal is indexed on PubMed Central, MedLine, the American Chemical Society's 'Chemical

\section{Dovepress}

Abstracts Service' (CAS), Scopus and the Elsevier Bibliographic databases. The manuscript management system is completely online and includes a very quick and fair peer-review system, which is all easy to use. Visit http://www.dovepress.com/testimonials.php to read real quotes from published authors.

Submit your manuscript here: http://www.dovepress.com/clinical-interventions-in-aging-journal 